We want to warm ourselves in this damp climate by radiant energy in luminous form. The coal fire is the cheapest source of such energy, but the time spent in tending to it and its dirt and the loss of health, etc., due to smoke pollution makes it, in truth, the dearest.

According to Prof. Bone, 89 per cent. of the energy of a ton of coal is secured after carbonisation at the gas works, in the gas 23 per cent., in the coke 60 per cent., in the tar, etc., 6 per cent. The modern radiant-heat gas fire gives us some 15 per cent. of the thermal energy of the coal used for producing the gas, and the efficiency of gas water-boilers is almost as high. From the coke, electric or steam power may be secured, giving 8-13 per cent. of the thermal energy of the coal, and then the tar products and the valuable manure, ammonium sulphate, are secured in addition, and the sky is not darkened, or our houses, clothes, and bodies polluted with smoke and ash. To use electricity generated from coal for heating is, as the late Lord Moulton said, "a ghastly waste," for from the present electric stations, only 8 per cent. of the thermal energy of the coal is secured, against some 25 per cent. secured by carbonisation at the gas works and the use of gas, coke and by products. By turning coke into electric power and supplying this power and gas for heating to every house, home industries can be revivied, and life made immensely happier in garden cities than it is at present spent in factories and one, two, or three-room tenement dwellings.

The coal crisis will be a blessing in disguise if it forces the nation to use gas, coke and smokeless fuel in place of raw coal, and thus clean the sky and conserve the national coal stores for foreign barter and future use.

\title{
Smoke Abatement.
}

By J. S. Owexs, M.D., A.M.Inst.C.E., F.G.S., Superintendent Advisory Committee on Atmospheric Pollution (Fellow).

I PROPOSE to deal very shortly with the cause and prevention of smoke as this aspect of the matter has been thoroughly dealt with many times recently, and this Congress is not so much an engineering as a sanitary one. I will, therefore, refer very briefly to a few of the main facts which are now beyond dispute.

Cause of Smoke.-The smoke from burning coal is always due to imperfect combustion but the loss of fuel represented in solid smoke is small, varying from, perhaps, a maximum of $\frac{1}{4}$ per cent. of the fuel burnt in boiler furnaces to 5 per cent. in open domestic fires. Smoke can only be formed from fuel containing volatile matter, hence the smokiness of a particular coal is to some extent a function of the amount of volatile matter contained. 
The two main sources of smoke are industrial furnaces and domestic fires. In the case of the former, smoke in any quantity results from either badly designed or over-worked furnaces, or bad stoking. The main point to bring out at present is that smoke from this source is practically entirely preventable without hardship. There may be one or two exceptions, such as furnaces for certain processes in the manufacture of steel, and pottery kilns.

Smoke produced from domestic fires is on quite a different footing, it is not possible, by any known means, to prevent smoke from an open grate burning bituminous or smoky coal ; the only remedy here is the burning of a smokeless fuel, which may be either gaseous or solid. I am aware that many claims are made for different grates but do not think I am overstating the case when I make the above assertion. The salient point to note here is that the prevention of smoke can only be attained by the use of smokeless fuel. Much has been said as to the relative merits of gas, coke and anthracite ; each has its particular advantages, and to some extent its own sphere of usefulness, but into this question I do not propose to enter. I would say, however, that of domestic fires the kitchen range is probably the worst offender, and would go so far as to suggest that the use of a kitchen range burning smoky coal should be prohibited.

Effect on the Atmosphere.-The chief aspect of interest to this Congress will doubtless be the effect of smoke upon the atmosphere, and for many years this has been a subject of much controversy, arising mainly from the fact that no accurate data were available to enable us to compare the state of the atmosphere at one place or time with another. That state of affairs has now been changed and accurate data are available, owing to the work of the Advisory Committee on Atmospheric Pollution. It is no longer possible for the producer of smoke to deny its effect upon the purity of the air, so that his attention is drawn towards attempts at proving the data are unsound or, alternatively, that the pouring out of impurities into the air is an essential to his work. Difficulties of the same kind arose when regulations were brought into force for preventing the pollution of drinking water.

Roughly speaking, a man consumes 30 to $50 \mathrm{lbs}$. of air per day, 2 to $3 \mathrm{lbs}$. of food, and 4 to $5 \mathrm{lbs}$. of water; that is, over four times as much air as food and water combined, yet the necessity for keeping the air pure is not yet fully realised, although much has been done of recent years to open the eyes of the public.

The two chief measurements aimed at by this Committee have been :-

(a) Deposit from the air.

(b) Suspended Impurities. 
Deposited Matter.--Dealing first with deposited matter: Although it is not a measure of total impurity it may be assumed to vary with this. It is easily measured, as all that is needed is an open topped gauge vessel with provision for catching everything which falls into it; the dust in fine weather and the rain in wet. The whole is removed monthly, weighed and analysed.

We have about 30 stations measuring deposit, but nearly all in cities.

To show the variation in the quantity of impurity deposited at different places, even when comparatively close together, I give the following table in which, opposite each station, is given the mean monthly deposit of solid impurity for the year ending March 31st, 1920 :-

Tons per sq. mile.

Southwark Park, London $39 \cdot 30$

Ravenscourt Park, London $36 \cdot 07$

St. Helens $\quad \ldots \quad \ldots \quad 35 \cdot 40$

Richmond Park, Glasgow $31 \cdot 10$

Tollcross Park, Glasgow $\quad 29.92$

Blythswood Square, Glas$\begin{array}{llll}\text { gow } \quad \ldots & \ldots & \ldots & 29 \cdot 26\end{array}$

Golden Lane, London ... $\quad 28 \cdot 88$

Botanic Gardens, Glasgow $27 \cdot 93$

Finsbury Park, London... $\quad 27 \cdot 60$

Victoria Park, Glasgow... 26.57
Tons per sq. mile.

Ruchill Park, Glasgow ... $24 \cdot 40$

Alexandra Park, Glasgow $24 \cdot 29$

Bellshouston Park, Glasgow $22 \cdot 71$

Meteorological Office, South

Kensington ... ... $21 \cdot 58$

Queen's Park, Glasgow ... $20 \cdot 51$

Victoria Park, London ... $19 \cdot 20$

Southport, Hesketh Park 16.41

Southport, Woodvale Moss 13.67

Rothamsted $\quad \ldots \quad \ldots \quad 10 \cdot 52$

$\begin{array}{lllll}\text { Malvern } & . . & \ldots & \ldots & 7 \cdot 02\end{array}$

It is not easy to realise exactly what these figures mean, but if we take the average deposit over London for the year ending March 31st, 1920, it amounts to about 40,000 tons. This is better than it has been, as in 1916 it came to about $\mathbf{5 5 , 0 0 0}$ tons, since when it has steadily diminished.

The following curve (Fig. 1) shows the deposit over London from 1915 to 1920 . of :-

This deposit in London when analysed is found to consist approximately

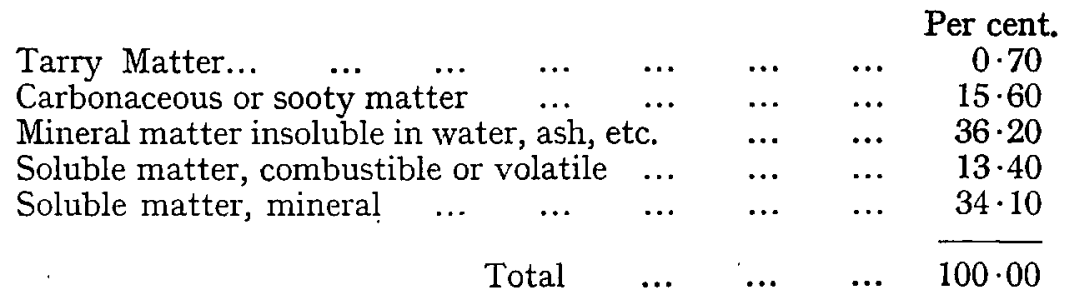

Suspended Matter.-A method of measuring suspended impurity in cities has been devised and has now been in continuous operation in London for some months. Briefly, the method consists in the use of an automatic 


\section{TOTAL SOLID MATTER DEPOSITED FROM}

\section{AIR OF LONDON FOR YEARS}

$1915-1920$

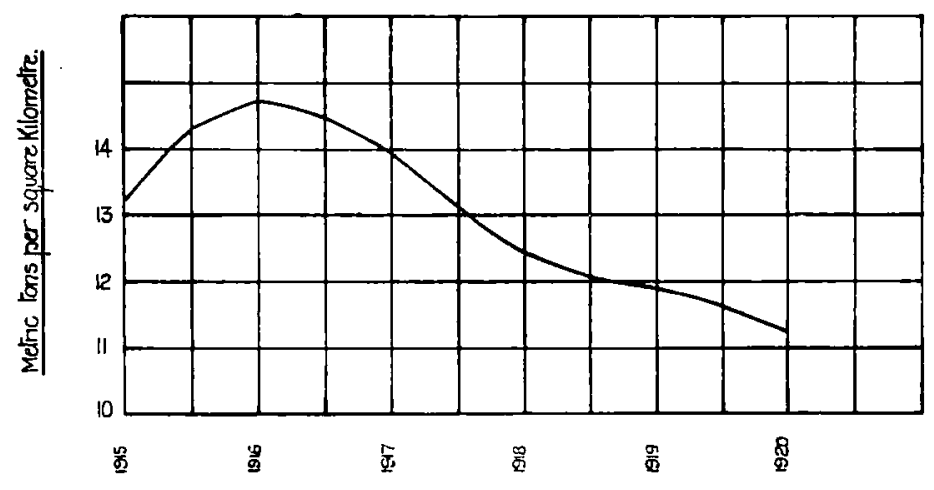

FIG. 1.

instrument (Fourth Report of the Committee for the Investigation of Atmospheric Pollution), which filters a fixed volume of air through a small disc of white filter paper at short intervals. The impurities are left behind on the paper, and, by the aid of a carefully calibrated scale of shades, provide a measure of the quantity of impurity in known units.

It will be realised that if matter is very finely divided and thrown into suspension in the air it may have little tendency to settle. When the diameter of the particles falls to, say, $1 / 20,000$ th of an inch, the very slightest disturbance of the air keeps them from settling. I have ascertained by measurement that a large proportion of the suspended matter of the air is below this size and varies between $1 / 100,000$ and 1/20,000th of an inch in diameter It, therefore, behaves almost like a gas and penetrates everywhere. Previous to measuring the diameter I had noticed that during a London fog or even an ordinary winter's day in London the record of impurity obtained on the standard instrument was the same, whether taken in a room with closed windows or outside, the fine suspended impurity penetrated into the room unless it was absolutely air tight

It is a common experience in London to find articles shut in drawers or cupboards covered with a layer of black deposit, even after a short time. This fine suspended dirt is in some respects more interesting than that which is deposited quickly. We breathe it into our lungs and retain some of it there, although fortunately, about 70 per cent. of it passes out again in the expired air. 
This passing out of dirt in expired air is a fact I commend to your attention. It is usually assumed that the nose and air passages completely cleanse the air of dirt, but this is not the case as I have found experimentally.

Systematic measurements of suspended impurity are now being made at the Meteorological Office, at Kew Observatory and at my office at 47, Victoria Street, Westminster, giving the state of the air at intervals of about fifteen minutes, night and day. From these records curves of impurity have been prepared and much useful information is being derived from a study of these curves.

Several such curves are now before you. Fig. 2. These show:--

* (a) Foggy days, divided into week-days (excluding Saturdays). Saturdays and Sundays.

(b) Ordinary days-similarly divided.

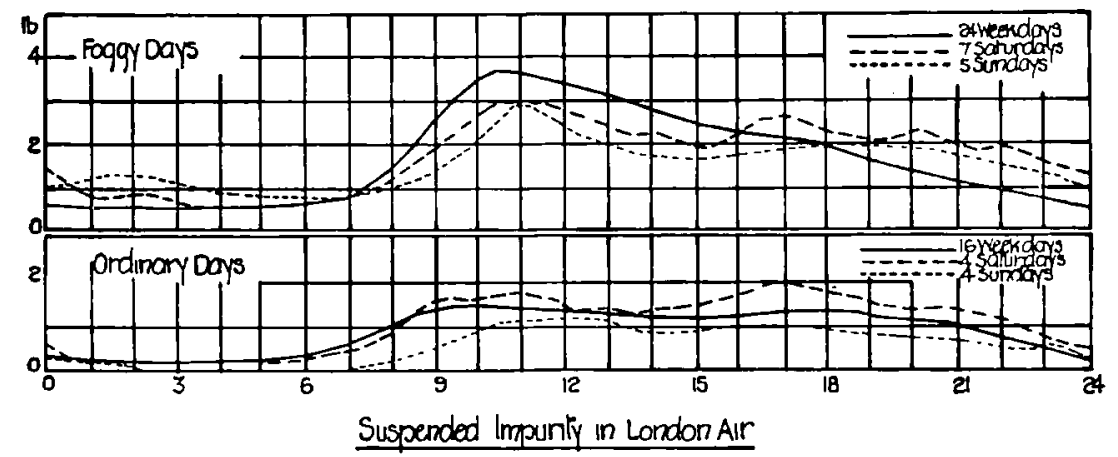

Vanation at Westminsier in the number of pounds of dirt in a looyard cube on selected days in the winter 1920-21.

FIG. 2.

Much has been said and many opinions given as to the relative importance of domestic and factory fires in contributing to atmospheric pollution. To show the importance of measurements such as we are making in solving such problems we will refer to the curves :-

It will be seen that certain features are common to all, namely a pure air between midnight and 6 a.m. while people are in bed, a rapid increase of impurity from $6 \mathrm{a}$.m. to about $10 \mathrm{a}$ a.m. when they are busy lighting and making up their fires, and a rapid fall in the impurity between 10 p.m. and 12 p.m. when they go to bed again. It is noteworthy that this rapid fall does not correspond with the hour of closing factories, say about 6 p.m., but that of letting out domestic fires.

* See Met. Mag. March 1921. 
Again, there is a noticeable peak about tea-time on nearly all the curves.

If we compare normal week-days with Saturdays and Sundays there is little difference in the amount of impurity although factories are closed most of the day on Saturday and all day on Sunday.

There is no remarkable falling off on Saturdays after 1 p.m., although most of the factories are shut about that hour.

On non-foggy Sundays there is a distinct delay in the maximum when compared with week-days, obviously owing to a later breakfast hour.

All these point towards the domestic fire as the chief source of atmospheric impurities. We have, therefore, a group of facts emerging from these curves each of which points in the same direction, and the cumulative evidence of which it is impossible to ignore.

Again, do these curves give any indication of a remedy apart from the general one that the domestic fire is the chief sinner? There is a very curious peak to be seen on all the curves about $10 \mathrm{a} . \mathrm{m}$. Why should such a peak occur? One might reasonably ask, are not the domestic fires burning all the afternoon and why then does not the impurity increase steadily all day?

When smoke is being poured out of London chimneys it very rarely, if ever, happens that it all can collect in the air over the city, there is usually a wind which carries some of it away. Under certain conditions, however, a large proportion may collect, or in other words smoke may be produced more rapidly than it is swept away by the wind.

Consider a normal London day when there is no absolute stagnation of the air, but a slow drift over the city into which drift thousands of chimneys are pouring their smoke, and at one point samples are being taken to measure the quantity of impurity. As long as the conditions remain steady, i.e., the rate of removal of smoke does not alter, the amount of impurity recorded will be a measure of the amount of smoke produced at that time, or rather a little before.

Should the rate of removal increase or diminish we would get a corresponding increase or reduction in the amount recorded.

We may take it then that unless the air is completely stagnant and the conditions prevent the removal of any smoke the records of impurity may be taken as records of rate of smoke production. This is very important, as if we look at the curves from this new point of view a remarkable new piece of information comes to light. That is, the time of the day at which the smoke emission is greatest is between 6 and 10 a.m. during the period when the fires are being lighted and before they have burnt up properly.

It would clearly tend to reduce the amount of smoke if the lighting period were hurried up by using plenty of wood, and a much greater effect 
would be obtained if the fires were lighted with some form of coke or semicoke.

If now a sufficient number of normal winter days be taken, that, is, days without conditions which cause that banking up of impurities resulting in smoke-fog, the corresponding curves may be regarded as showing relative smoke production. Further, since rate of smoke production multiplied by the time gives total smoke produced, the areas enclosed between the curves and the base are proportional to the total smoke produced in 24 hours.

On week-days we have both domestic and factory fires in operation, while on Sundays we have domestic fires only, or practically so, hence the area enclosed by the curve for non-foggy Sundays deducted from that for non-foggy week-days should give, in some unit, the smoke produced by factories on week-days. If, then, $W$ is equal to the area of the week-day curve, and $\mathrm{S}$ is equal to that of the Sunday curve, the proportion of domestic smoke to factory smoke in the air of London is approximately equal to $\frac{\mathrm{S}}{\mathrm{W}-\mathrm{S}}$. The assumption is made that the amount of domestic smoke produced on Sundays is the same as on week-days. Two places were examined, Westminster and South Kensington. In the former the mean of 11 Sunday records and of 46 week-days were used, giving a ratio of $2 \cdot 25$ domestic to 1 factory smoke.

In South Kensington, 7 Sundays and 39 week-days were used, and the ratio came out as $2 \cdot 15$ domestic to 1 factory smoke. This is believed to be the first time a reasonably reliable method has been made available for fixing the relative importance of factory and domestic fires as sources of atmospheric pollution.

These points will show the practical value that such a research may have.

I have referred above to the drift of smoke away from the city. The following explanation of London smoke fog may be of interest. Soot particles are heavier than air and depend on the hot chimney gases to lift them up; these hot gases can continue to rise so long as the surrounding air is colder. The temperature near the ground is usually higher than at some distance up and thus hot air rising passes from warm to cold air ; and, although on rising it expands and cools, it may always be warmer than the surrounding air and can thus continue to rise. If, however, the temperature gradient is reversed and it is cooler near the ground than higher up, the rising gases from a chimney may soon reach air of a temperature as high as their own and thus can rise no higher. The smoke collects at this level and we have a smoke fog. Whether the smoke lies down in streets or hangs as a cloud overhead will depend upon the temperature 
distribution. If the smoke can rise high enough above the city it is sure to meet an air current to carry it off.

To produce a dense smoke fog about 4 milligrams of soot per cubic meter of air is all that is required. 1 milligram produces the ordinary haze which we have most of the winter in London. These quantities correspond to about 7 lbs. and 1.7 lbs., respectively, per million cubic yards. Or, if a dense smoke fog extends over the whole of London and up to a height of 400 feet something under 200 tons of soot would be present.

I have calculated that the domestic fires of London during the hours from 6 a.m. to 9 a.m. produce over 200 tons of soot. Thus it is obvious that there is quite enough to give us one of our densest fogs, if the atmospheric conditions prevent its removal.

Dr. JAMes WheAtLEy (Salop C. C.) emphasised the importance of basing public health work on physiology. The important thing was to get overwhelming evidence of the harmfulness of a smoke-laden atmosphere, and to form a strong public opinion so as to force the Government to take energetic action. The health and fitness of the nation did not depend upon treatment, however early, but on food, exercise under good conditions, and pure air. Their efforts should be directed to improving the conditions particularly by the education of the public, whilst treatment and hospitals should be relegated to their proper position in their public health schemes.

Dr. E. G. ANnis (Greenwich) referred to the greater need for educating the general public as to the value of night air as the diagrams show this air contains far less impurities than ordinary air in daytime, and also to the advantage to be gained by using low temperature carbonised coke, i.e., coalite. He doubted the advantage, from the point of smoke abatement, of using oil for industrial purposes, judging from the results when their destroyers were using oil they were able to produce smoke or no smoke at will, but, apparently, this was not so in industrial concerns, as judged by a large concern, i.e. (L.C.C. Generating Station), in his district

Mr. DAVID R. CAMPBEIL (Belfast) emphasised the need for centralized production of heat and energy, and also the encouragement of communal cookery. Use of peat was desirable as tending to some slight reduction of nuisance.

Dr. W. Bertray Hill (Selby) urged that additional legislation was needed to enable them to deal with excessive smoke from domestic chimneys, which, in the greater proportion of instances, were the chief offenders. Proceedings could be taken against a factory, but not a house.

Mr. D. PUGH-Jones (Cardiff) suggested the more general use of anthracite coal for domestic purposes, as this could easily be burnt in all kinds of grates. It was used in practically every house in Carmarthenshire in every type of grate. 